\title{
ONLINE GROCERY RETAILING IN GERMANY: AN EXPLORATIVE ANALYSIS
}

\author{
Christian SEITZ1 ${ }^{1}$, Ján POKRIVČÁK ${ }^{2}$, \\ Marián TÓTH ${ }^{3}$, Miroslav PLEVNÝ 4 \\ 1,2 Department of Economic Policy, Faculty of Economics and Management, \\ Slovak University of Agriculture in Nitra, Tr. Andreja Hlinku 2, 94976 Nitra, Slovakia, \\ ${ }^{2,4}$ Department of Economics and Quantitative Methods, Faculty of Economics, \\ University of West Bohemia in Pilsen, Univerzitni 22, 30614 Plzeň, Czech Republic \\ ${ }^{3}$ Department of Finance, Faculty of Economics and Management, \\ Slovak University of Agriculture in Nitra, Tr. Andreja Hlinku 2, 94976 Nitra, Slovakia \\ E-mails: ${ }^{1}$ c.seitz@ffponline.de; ${ }^{2 j p o k r i v c a k @ y a h o o . c o m ; ~}{ }^{3}$ marian.toth@uniag.sk; \\ 4plevny@kem.zcu.cz (correspondingauthor) \\ Received 07 August 2017; accepted 23 November 2017
}

\begin{abstract}
The paper focuses on the German food retailing industry with its market characteristics and the status quo of online food retailing in Germany by analysing data from market research institutes and consumer direct questionnaire. The paper examines the consumers' perceptions of online as well as offline grocery shopping. As a result, an online grocery model was created using PLS-SEM modelling. It illustrates all major success factors related to the consumer's willingness to shop for groceries online in Germany. The main factors influencing the willingness to shop for groceries online are awareness of benefits, need for more convenience, and change of the lack of trust in the new distribution channel. We identified some consumer groups that are more open to online shopping as they benefit more from online grocery shopping. Especially working mothers and young professionals are the consumer groups with a high potential interest.
\end{abstract}

Keywords: online grocery shopping, e-commerce, online grocery, on-line food retail, consumers' perceptions, Germany.

JEL Classification: L110, D470.

\section{Introduction}

Over the past decade the Internet has changed life of today's society more than any other media. Among others, within a short period of time, the Internet has become a major distribution channel, where customers can browse through shops and retailers can offer their merchandise and services online. Today, presence in the digital marketplace is essential for retailers, also in the food retailing industry. In many European economies online food retailing continues to grow. However, in Germany the market share of online food retailers is limited. The term "retailing" comprises of all those final activities and steps needed either to serve the final consumer with a product made elsewhere 
or to provide a service to the consumer (Dunne et al. 2011). Retailing is understood as a set of activities that increase the value of the goods and services sold to the final consumers for their private, non-commercial use. This implies that sales for industrial or business use are not considered as retail transactions (Cox, Brittain 2004). Based on this definition of retailing, the food retail industry can be defined as follows: food retail business or food retailing is a collective term for retailers, which primarily carry food products in their assortment. Besides food products, food retailers also carry non-food consumer goods in their product range, but the food articles occupy a wider range than the non-food articles (Bogner, Brunner 2007).

In Germany in 2012, approximately 42.3 million people, which is 74 per cent of all Internet users with the age over 10 years bought or ordered goods or services for private use over the Internet (Statistisches Bundesamt 2012). This study focuses on the German food retailing industry with its market characteristics and the status quo of online food retailing in Germany.

\section{Online grocery shopping and business models}

Using online shops retailers aim to retain existing customers and gain new customers in the increasingly competitive retail environment (Kabadayi et al. 2007; Neslin, Shankar 2009; Simová, Cinkánová 2016). In the US and many European economies online food retailing continues to grow (see e.g. Daniels (2017) or Henry (2015)). However, in Germany the market share of online food retailers is limited. According to He et al. (2008), a lack of intention to purchase online is the main obstacle in the development of electronic commerce. Lim et al. (2016) investigate factors influencing customer's online shopping behaviour by Structural Equation Modelling. They found that subjective norm and perceived usefulness of online shopping have a significantly positive influence on online purchase intention. The customers are expected to benefit most from the ease and convenience of online shopping, as compared to the conventional (offline) shopping (Bunker, MacGregor 2000). The gradual transition of social relations from the real world into the Internet is also reflected in increasing sales generated via online retailing (Heinemann, Schwarzl 2010).

Suitability of different products or services for the online retailing differs, however. Koch and Cebula (2002) point out four categories of products that are less likely to be sold online: (1) products which involve touch, taste or smell, (2) the sale which requires custom fitting, (3) the sale which is from a catalogue or (4) the sale which is accompanied by advice or counsel.

The two main important characteristics positively affecting suitability of the products or services for online retailing are the potential for transaction cost reduction and the autonomy of the buyer. The potential for transaction cost reduction refers to the savings in transaction costs of the online shopping relative to conventional shopping. The autonomy of the buyer can be defined as the self-service potential of the buyer, or to what extent the buyer needs professional assistance with the sale. In general, the higher the potential for transaction cost reduction and the greater the autonomy of the buyer, the better the product is suited for the online distribution channel (Ahlert et al. 2001). 
A few studies have been published concerning the German online grocery retailing yet. Study conducted by Ernst and Young (2014) stresses that the size of the retailer and gaining consumers trust are important factors for a successful online grocery shopping. Fedoseeva et al. (2017) state the price dispersion exists both between online and offline grocery providers as well as across online retailers. Fittkau and Maaß (2014) conclude that convenience, no queues, being free from opening hours, and a large choice of specialties are the major factors that bring consumers online.

So far, German food retailers have largely neglected online retailing of groceries. In other developed economies, online grocery is more developed than in Germany. In the USA, for example, a quarter of all American households have bought groceries online at least once. In the UK, online grocery sales amount to a market share of $3 \%$ of total British food retailing (Lebensmittelzeitung 2008). In contrast, the market share of online grocery retailing amounted only to $0.2 \%$ of the total revenue of the German food retail sector in 2011. Around $80 \%$ of German consumers have no experience at all with shopping for groceries online. Less than $1 \%$ actually does their weekly grocery shopping in an online food shop (Plachetta, Röttig 2012). Product quality is always an important aspect of the purchasing decision, but the importance of quality is even more important when shopping over the Internet. For retailers, research shows that online markets facilitate increased competition (Malone et al. 1987; Bakos 1997).

From the perspective of retailers, there are four main online grocery business models (ATKearney 2012). Retailers can rely on the existing stores or use warehouses. Retailers either deliver ordered goods to the customers from their existing stores or offer the customer pick-up service of pre-ordered groceries at the existing stores. In warehousebased online grocery shopping retailers deliver directly from warehouses, or customers pick-up ordered groceries in a drive-through at the warehouse. On the other hand, consumers differentiate between three types of online shopping: delivery, pick-up or drive-through. These three options are further considered in the paper.

We focus on the consumer's perspective regarding the demand for online grocery shopping. We study the motives driving consumers to shop for groceries online and consumers' demand for online food retailing. We do not study the supply of online grocery shopping by retailers and their perspective on online grocery, like economic efficiency and profitability. Since the online grocery business in Germany is only in the early stage of development, the paper is understood as an explorative analysis. It sets the goal to explore all major motives of German consumers' that affect the willingness to engage in online grocery. Based on this analysis of the consumer's motives we derive an online grocery model, which illustrates all major success factors relating to the consumer's willingness to shop for groceries online.

\section{Hypothesis development}

It is important to understand the drivers behind the German consumers' grocery shopping behaviour. How consumers evaluate the advantages and disadvantages of online vs. offline stores are important for development of online grocery shopping in Germany. 
Also costs and anxieties, such as delivery fees, that deter consumers from shopping for groceries online are analysed. We also study the barriers for online grocery shopping. Moreover, it is crucial to assess which consumer groups are most likely to buy groceries online and why. Therefore we analyse the consumer's motives, i.e. the reasons for a consumer to shop or not to shop for groceries online, and the consumer's expectations of this service.

In the literature grocery shopping is often described as a routine and pragmatic activity with a missing 'pleasure' dimension (Lebensmittelzeitung 2008). Consumers, therefore, tend to allocate few cognitive resources to grocery shopping and rather follow their previous shopping decisions, which require minimum effort (Picot-Coupey et al. 2009). On the one hand, grocery shopping is perceived as a necessary everyday task which is physically and psychologically stressful and has to be carried out (Seitz 2013) while on the other hand, some people perceive grocery shopping as an inspiring journey through the grocer's multi-facetted and colourful product assortment and also as a welcome opportunity to be among people. Based on this we hypothesize:

H1: Most German consumers perceive grocery shopping to be a tiresome duty as part of everyday life.

Based on the different perceptions of grocery shopping, some consumer groups show a higher propensity to shop for groceries online than other consumer groups. In the previous research attention is paid to the differences based on age and gender (Seock, Bailey 2008; Keh, Shieh 2001). There are also cultural differences among countries that are reflected in the interest in online grocery shopping (Goethals et al. 2009). Some consumer groups could benefit from the time-saving of online shopping due to their limited amount of time, while others can benefit from the convenience of the online shopping due to their physical impairment and reduced mobility. The persuasion of the former group to become loyal customers can be strongly influenced by highly sophisticated business continuity strategies (Podaras et al. 2016) which can guarantee the continuous availability of the online services and the involved web tools. Therefore we identify consumer groups in Germany who are more likely to shop online and anticipate:

H2: Some consumer groups in Germany are more likely to shop for groceries online than other consumer groups.

Studies focus also on the reasons and motives for online grocery shopping. The two main motives are convenience and time savings (Boyer, Hult 2005; Hand et al. 2009; Jayawardhena, Wright 2009). Online channel offers a more convenient possibility of grocery shopping, which could replace the visit of the supermarket:

H3: The main motive for most German consumers to shop for groceries online is the need for more convenience.

Grocery shopping in a conventional store has been a long learned and habitual behavioural pattern for several decades and therefore deeply anchored in the consumers' mind-set (Szász 1999). As a result, these grocery shopping habits are relatively stable and thus, hard to change. The online channel represents a break with the traditional shopping routines and we offer the following hypothesis: 
H4: The main hindrance for most German consumers to shop for groceries online is the lack of trust and confidence in the e-grocer and the digital marketplace.

When shopping online, customers cannot pick products by themselves. Instead, retailer makes the final decision which particular product is selected. Customers might distrust the retailer with respect to the selection of products (Picot-Coupey et al. 2009). Consumers are usually picky, sceptical and cautious, when food shopping is concerned. Fresh produce, like fruits and vegetables, chilled products, like fresh fish or meat, and dairy products, like fresh milk and cheese, are screened carefully before they are found to be good. When shopping for groceries through the online channel, however, consumers must leave such a delicate decision to the e-grocer and we hypothesize:

H5: The vast majority of German consumers is reluctant to shop for fresh produce and chilled products through the online channel.

Online grocery shopping is affected by costs related to logistics. Consumers however do have low willingness to pay for home delivery (Teller et al. 2006). As a result of the strong market position of discounters in Germany, food prices are low in Germany relative to other industrialized economies, like the UK or the USA. Due to price sensitivity, the majority of consumers might not be willing to pay a fee for the e-grocery service and we assume:

H6: The vast majority of German consumers is not willing to pay a fee for the e-grocery service.

There are several delivery models for online grocery shopping (Punakivi et al. 2001) and how the grocery gets to the customer might be an important barrier for online grocery development (Boyer, Hult 2005). From the consumer's point of view, home delivery combines most advantages of all business models of online grocery shopping. Since it is assumed that consumers prefer the highest possible level of convenience, home delivery appears to be the most preferable business model. Moreover, home delivery is simply the best known business model. German consumers already have experience with this kind of online shopping, while the drive-through counters and the in-store pick-up are largely unknown and thus consumers might be rather sceptical about them.

H7: German consumers prefer home delivery over drive-through and in-store pick-up.

The distribution of groceries to consumers requires certain precautions. First, the distribution process must be fit to handle all concerns regarding quality standards, like temperature or spoilage. Second, consumers want to obtain groceries quickly, which is usually the same day when ordered. Third, and most important, the biggest advantage of the online channel is convenience or easing the burden. Inflexible and wide delivery time windows, however, would counteract these benefits. High expectations on delivery can include flexible delivery times and narrow delivery time slots. We assume:

H8: Most German consumers have high expectations of the delivery conditions. 


\section{Material and Methods}

To collect the data, a survey using a standardized written questionnaire was used. The respondents were directly questioned about their attitudes and opinions regarding online grocery shopping.

\subsection{Questionnaire construction and gained data}

We constructed the questions based on a theoretical framework, and previous research as reflected in the section on development of hypotheses. An opinion about potential consumer's distrust as he/she cannot feel, touch and smell products like fruits and vegetables themselves but he/she have to leave the final choice to the retailer was included to the questions related to benefits and barriers of online grocery shopping (Picot-Coupey et al. 2009). There are some customers that take pleasure in shopping for groceries but, on the contrary, the online grocery shopping offers the possibility to free consumers from the physical burden and is less time consuming (Levy, Weitz 2004). On one hand, there is an overall agreement concerning online shoppers in general that they appreciate and highly value the convenience of the online channel and therefore are happy and willing to pay for the extra service (Kotzab, Teller 2005). Past experience also showed that consumers are willing to invest in machines, devices and tools that help them save time and efforts, e.g. microwave ovens, washing machines or dish washers (Tanskanen et al. 2002). On the other hand, consumers tend to expect lower prices online rather than offline. So far mostly low prices rather than additional service or a brand name have encouraged German consumers to purchase groceries (Passenheim 2003).

There are four groups of questions in our questionnaire. The first group of questions deals with the respondent's attitudes towards conventional grocery shopping. Second group of questions is about online shopping in general and third group of questions specifically addresses the respondents' attitudes and perceptions towards online grocery shopping. Finally, part four of the questionnaire is used to collect relevant data on the respondent, e.g. age or number of members of their households and was used to divide respondents into subgroups. Both nominal and ordinal scales were used. The survey was conducted in December 2012 and January 2013 in front of 21 diverse types of grocery stores. Thereby, the opinions and attitudes of diverse types of grocery shoppers that usually shop at a particular supermarket could be surveyed, e.g. bargain hunters usually shop at discounters, variety seekers often visit full-range supermarkets, etc. Moreover, the survey was conducted in the same region at the randomly chosen grocery stores in the countryside (10) and at grocery stores in urban (6) and suburban (5) areas.

The sample size consisted of 412 participants. Most participants were between 40 and 65 years old (38\%), whereby participants over 65 years old were the least represented (8\%). Participants aged between 14 to 25 account for $26 \%$ and participants aged from 26 to 39 are equal to $28 \%$. A total of $39 \%$ of the participants were male and, consequently, $61 \%$ were female. This unequal distribution is due to the fact, that women in Germany are more interested in grocery shopping than men, since in most households, the woman is responsible for the nutrition of the family. Almost half of the respondents 
live in rural areas (51\%) and 49\% live in urban districts. The majority of respondents had no children $(55.1 \%), 15.3 \%$ of participants had one child, $20.4 \%$ had two and only $7 \%$ had three children. Four or more children account for only $2.2 \%$.

\subsection{Methods used}

The confidence interval (CI) is used to test the reliability of the results. The CI level states the probability value is associated with the confidence interval and is calculated as $100(1-\alpha)$, where $\alpha$ lies between 1 and 0 . In this paper $\alpha=0.05$, i.e. the success rate of the applied method is $95 \%$.

Fisher's exact test is used to test for the independence of categorical variables. We use it to test whether different consumer groups are independent with respect to online grocery shopping behaviour. The Fisher's exact test assesses the independence of two variables (i.e. association), but does not measure the actual magnitude of this relationship (Little 2013).

The principal component analysis (PCA) is used in order to reduce the number of observed variables to a smaller number of principal components, while the original information is retained as much as possible. The factor extraction is based on Kaiser's criterion, i.e. all factors with eigenvalues greater than 1 are retained. Kaiser's recommendation is based on the idea that, since the eigenvalue represents the amount of variation contributed by a factor, an eigenvalue of 1 represents a substantial amount of variation.

We use structural equation model (SEM) to estimate the willingness to shop for groceries online. SEM modelling is often used in marketing and management research. It enables to simultaneously examine a series of interrelated dependence relations between a set of variables while accounting for measurement error (Rigdon 1998).

There are two methods of SEM: the covariance-based SEM (CB-SEM) and the partial least squares SEM (PLS-SEM). In this paper, PLS-SEM is used to estimate path relations (coefficients) between the variables in the model, while aiming at minimizing error terms of the endogenous constructs. The PLS-SEM model estimates the theoretically established cause-effect relationship between motives and factors affecting the willingness to shop grocery online. The PLS-SEM is a prediction oriented approach and is less data and specification of relations demanding than the CB-SEM (Rigdon 2012; Dijkstra 2010). The PLS-SEM has two parts: an outer and an inner model.

The outer model consists of indicators, which in our case were observed by questionnaire. The method distinguishes two types of indicators: reflective and formative. Reflective indicators are caused by the inner model constructs and cover questions related to the opinions on online grocery shopping of the questionnaire. Formative indicators cause the construct of the inner model and in our case they were observed in questions related to the characteristics of the respondents.

The inner model includes all dependent variables and independent constructs of the final model characterizing in our case the final dependent variable willingness to shop for 
groceries online. In PLS-SEM constructs reflect the theory and results of the questionnaire conducted in our case.

In PLS-SEM, the arrows (between constructs as well as between constructs and their assigned indicators) are considered to be predictive and also, based on strong theoretical evidence, can be interpreted as causal relationships. PLS-SEM first calculates all the outer model results, which describe the relationships between the constructs and their indicator variables. Second, PLS-SEM calculates the path coefficients, which are the relationships between the constructs in the inner structural model.

PLS-SEM delivers the estimates for all relationships in the outer model (i.e. the loadings and weights) as well as in the inner model (i.e. the path coefficients). The standardized coefficients lie between -1 and +1 , meaning that path coefficients close to +1 indicate a strong positive relationship, while coefficients close to -1 indicate a strong negative relationship.

In addition to the path coefficients, the PLS algorithm also calculates the $\mathrm{R}^{2}$ values for each endogenous construct (also called latent variable (LV)). Endogenous LVs serve as dependent variables, while its direct predecessors serve as independent variables. Hereby, $\mathrm{R}^{2}$ values represent the percentage of the explained variance of the dependent variable. $R^{2}$ values are normed between 0 and +1 . To verify the model, we tested the relevance and significance by a nonparametric bootstrapping procedure. Based on the results of the bootstrapping procedure, a Student's empirical t-test was applied.

\section{Questionnaire analysis and findings}

In our survey only $26.5 \%$ of the respondents perceive store-based grocery shopping to be a tiresome duty, while for $51.1 \%$ of the respondents the experience from shopping might be positive and mainly dependent upon their current circumstances, for $11.4 \%$ grocery shopping is inspiring and for $10.9 \%$ it is a welcome opportunity to be among people. German consumers simply do not perceive grocery shopping to be a tiresome and annoying routine duty as was originally assumed, but it mostly depends on the personal situation. We reject Hypothesis 1.

The majority of German consumers is not familiar with the concept of e-grocery due to the low awareness-level of the already existing e-food shops. Results of the questionnaire did show that $89.8 \%$ of the respondents are not familiar with the concept of online grocery. There are differing interests in online grocery by consumer groups. We divided respondents into five groups. The classification arises from the fourth group of questions in the questionnaire collecting information on the respondent. We use following groups of consumers:

- Working mothers (females, work a part-time or full-time job, have at least one child and are familiar with online shopping);

- Young professionals (up to 39 years old, income is at least average or higher, have no children and are familiar with online shopping);

- SilverSurfers (aged over 65, familiar with online shopping); 
- Others (every respondent not identified as a working mother, young professional or SilverSurfer);

- Groups combined (working mothers, young professionals and SilverSurfers).

Different consumer groups have different interests in online grocery shopping. It follows from the survey results that $85.5 \%$ of respondents of the Groups combined which included Working mothers, Young professionals and SilverSurfers show potential interest in online grocery shopping. From the group Others $57.1 \%$ of respondents are interested in online shopping, while $77.1 \%$ of the Working mothers, $92.7 \%$ of the Young professionals and $85.7 \%$ of the SilverSurfers show interest in online grocery shopping and also have already considered buying their groceries online.

Fisher's exact test confirmed a significant association between the Working mothers and the potential interest in online grocery shopping at 90 per cent significance level. Similarly, there is a highly significant association between the Young professionals and the potential interest in online grocery, $p$ (two-tailed) $<0.001$. However, according to Fisher's exact test there is no statistically significant association between the SilverSurfers and the potential interest in online grocery, $\mathrm{p}$ (two-tailed) $<0.245$.

Working mothers and young professionals could profit from the time-saving of online shopping due to their limited amount of time, while SilverSurfers could benefit from online grocery shopping because of their impaired physical mobility and handling of heavy items. Results are in line with Hypothesis 2.

Grocery shopping in a conventional store takes time. Consumers would rather do something else than grocery shopping, like work, rest, or play and entertain (Picot-Coupey et al. 2009). Consumers are generally not willing to devote disproportionate effort to grocery shopping, e.g. travelling long distances, evaluating products prior to purchase etc. (Levy, Weitz 2004). The online channel offers a more convenient alternative. Convenience factors of online grocery shopping are considered to be more important than lifting of the physical burden of shopping. Convenience factors of online grocery shopping include independence from opening hours, ease of ordering, no queuing, saving time. More than $50 \%$ of German consumers vote 'convenience' as their prime motive to shop for groceries online. Also, the factor 'convenience' is by far considered the most important motive in comparison with the other identified factors. The following ranking shows the mean percentage of each respective factor and its confidence interval:
1. 'Convenience' $70.9 \%$ (CI $68.0 \%-73.8 \%)$
2. 'Lifting physical burden'
$57.0 \%$ (CI 52.2\%-61.8\%)
3. 'Efficient \& selective shopping'
$43.4 \%$ (CI $38.6 \%-48.3 \%)$
4. 'Mental stress within store'
$29.9 \%$ (CI 26.3\% - 33.4\%)

Results confirm Hypothesis 3 that the main motive for most German consumers to shop for groceries online is the need for more convenience.

The online channel represents a break with traditional shopping routines. There are many impediments to online grocery shopping (Veselý, Dohnal 2016). In our survey we explicitly asked about eight of them (insecurity, no control of freshness and quality, lack of feel, touch and smell, higher prices, high delivery costs, less going out, lack of shopping atmosphere or inspiration, happy with the status quo). 
A principal component analysis (PCA) was conducted on the eight items using a varimax rotation method with Kaiser Normalization (Field 2012). Three components had eigenvalues over Kaiser's criterion of 1 and in combination explained $66.93 \%$ of the variance, as shown in Table 1.

Table 1. Principal component for impediments to shop for groceries online

\begin{tabular}{|c|c|c|c|}
\hline & \multicolumn{3}{|c|}{ Component } \\
\hline & 1 & 2 & 3 \\
\hline QIII.3.4. Insecurity/No information? & 0.799 & & \\
\hline QIII.3.3. No control of freshness and quality? & 0.789 & & \\
\hline QIII.3.5. Lack of feel, touch and smell? & 0.755 & & \\
\hline QIII.3.6. Higher prices? & & 0.862 & \\
\hline QIII.3.7. High delivery costs? & & 0.854 & \\
\hline QIII.3.1. Less “going out”? & & & 0.822 \\
\hline QIII.3.2. Lacking shopping atmosphere/inspiration? & & & 0.791 \\
\hline QIII.3.8. No need to/Happy with status quo? & & & \\
\hline
\end{tabular}

The cluster of items suggests that component 1 represents 'Lack of trust', component 2 represents 'Higher costs and prices' and component 3 represents 'Lack of shopping experience'. The item 'Happy with status quo' stands on its own. The PCA could not cluster this component with other components. However, it certainly makes sense to consider this factor in the following analysis of the CI's, since the happiness with the status quo is certainly an important issue. The following ranking shows the mean percentage of each respective factor and gives the confidence interval in brackets (multiple answers in this question allowed):
1. 'Lack of trust'
$73.3 \%$ (CI $70.3 \%-76.3 \%)$
2. 'Happy with status quo'
$71.6 \%(\mathrm{CI} 67.2 \%-76.0 \%)$
3. 'Lack of shopping experience'
$50.0 \%$ (CI $45.9 \%-54.1 \%)$
4. 'Higher costs and prices'
$42.6 \%$ (CI $38.5 \%-46.7 \%$ )

The results of the confirmatory analysis are in line with the preliminary result of the descriptive analysis and we accept Hypothesis 4 that the main hindrance for most German consumers to shop for groceries online is the lack of trust and confidence in the e-grocer and the digital marketplace.

The results of our survey confirm the hypothesis that the willingness to engage in online shopping depends on the type of the products. The vast majority of German consumers, for example, show no reluctance to shop for toiletries, snacks, candies or beverages. A principal component analysis was used in order to group the diverse categories of foodstuff according to their degree of reluctance for being purchased online. Three components had eigenvalues over Kaiser's criterion of 1 and in combination explained $60.59 \%$ of the variance, as shown in Table 2 .

The cluster of items suggests that component 1 represents 'Problematic foodstuff', component 2 represents 'Unproblematic foodstuff' and component 3 represents 'Toiletries'. 
Table 2. Principal component for the German consumer's favour/scepticism towards diverse foodstuff categories in the online channel

\begin{tabular}{|c|c|c|c|}
\hline & \multicolumn{3}{|c|}{ Component } \\
\hline & 1 & 2 & 3 \\
\hline QIII.4.1. fresh produce (vegetables \& fruits) & .888 & & \\
\hline QIII.4.7. chilled food and dairy products (e.g. milk, butter, yogurt) & .835 & & \\
\hline QIII.4.2. fresh meat and fish & .796 & & \\
\hline QIII.4.4. staple foods (e.g. rice, noodles) & & .772 & \\
\hline QIII.4.6. canned food & & .757 & \\
\hline QIII.4.10. snacks and candies & & .731 & \\
\hline QIII.4.8. bakery products and pastries & & .561 & \\
\hline QIII.4.9. alcoholic and non-alcoholics beverages & & .521 & \\
\hline QIII.4.5. toiletries (e.g. toilet paper, swaddling bands) & & & .895 \\
\hline QIII.4.3. frozen food & & & \\
\hline
\end{tabular}

The items 'Frozen food' stands on its own, which may be due to the fact that German consumers meanwhile have accustomed to buy frozen food in catalogue sales and online shops. According to the PCA, this item cannot be clustered with other components. However, we included this factor in the following analysis of the CI's, since frozen food is certainly a meaningful issue. The results of the PCA determine the following categories of equal reluctance or, respectively, favour to buy this category online.

The following ranking shows the mean percentage of each respective factor and gives the confidence interval in brackets (multiple answers in this question allowed):
1. 'Problematic foodstuff'
$94.3 \%$ (CI $92.4 \%-96.3 \%)$
2. 'Frozen food'
$76.2 \%$ (CI $72.1 \%-80.3 \%)$
3. 'Unproblematic foodstuff'
$59.9 \%$
(CI $56.8 \%-63.1 \%)$
4. 'Toiletries'
$26.0 \%$ (CI $21.7 \%-30.2 \%)$

As a result, it appears that German consumers are cautious with respect to online grocery shopping especially in shopping for chilled products or fresh produce. We confirm Hypothesis 5 that the vast majority of German consumers is reluctant to shop for fresh produce and chilled products through the online channel.

Low prices rather than additional service or brand names have encouraged German consumers to purchase groceries (Passenheim 2003). Discounters have a strong market position in Germany and most German consumers take low prices for granted. Due to this price sensitivity, the German consumers might not be willing to pay a fee for the online grocery service. Therefore we investigated whether the consumers are willing to pay a fee for online shopping.

The results of the survey show that consumers' willingness to pay differs among online business models. Most German consumers are willing to pay for home delivery $(84.5 \%)$, whereas fewer consumers are willing to pay for pick-up at a conventional store (36.2\%) or pick-up at a drive-through counter (36.7\%). The confidence interval for the mean 
percentage of the willingness to pay for online grocery was calculated. Since the willingness to pay is expected to differ depending on the choice of the business model, the confidence interval was calculated separately for each business model.

First, the confidence interval for the mean of the unwillingness to pay for home delivery was calculated. It lies between the lower boundary of $12.0 \%$ and the upper boundary of $19.0 \%$, with a mean of $15.5 \%$. Only $\sim 15.5 \%$ consumers are not willing to pay for home delivery.

Second, the confidence interval for the mean of the unwillingness to pay for a pick-up at a conventional store was calculated. It lies between the lower boundary of $59.2 \%$ and the upper boundary of $68.5 \%$, with a mean of $63.8 \%$. This means that $63.8 \%$ consumers are not willing to pay for a pick-up at a conventional store.

Third, the confidence interval for the mean of the unwillingness to pay for a pick-up at a drive- through counter was calculated. Confidence interval has the lower boundary of $58.7 \%$ and the upper boundary of $68.0 \%$, with a mean of $63.3 \%$. Approximately $63 \%$ consumers from the sample are not willing to pay for a pick-up at a conventional store and we confirm Hypothesis 6.

The two pick-up options achieve almost equal willingness to pay, which hints at an equal status of the two pick-up options, whereby the willingness to pay is higher for home delivery.

Home delivery appears to be the most preferable business model from consumer's perspective. German consumers already have experience with this kind of online shopping, while the drive-through counter and the in-store or warehouse pick-up are largely unknown and require more time and effort from consumers.

Our survey results show that German consumers clearly prefer home delivery (83\%) to the drive-through pick-up ( $9 \%$ ) or in-store pick-up (8\%). The 95 per cent confidence interval lies between the lower boundary of $78.8 \%$ and the upper boundary of $86.2 \%$. As stated in the Hypothesis 7 home delivery is the most preferred business model and consumers have the highest willingness to pay for this business model.

The results of the survey show that most German consumers have high expectations of the delivery conditions. For German consumers, it is most important to determine delivery times themselves according to their personal schedule $(81.1 \%)$ and also to be provided with a certain degree of flexibility for delivery times (73.7\%). A narrow window for the delivery time, however, is not considered as important (54.9\%).

The confidence interval for the mean percentage of the expectations of each delivery condition was calculated. Obviously, there is a clear ranking of importance of the delivery conditions:

1. 'Determining delivery times by consumers themselves'

2. 'Flexible delivery times'

3. 'Narrow delivery time windows'

$$
\begin{aligned}
& 81.1 \%(\text { CI } 77.3 \%-84.9 \%) \\
& 73.8 \% \text { (CI 69.5\%- 78.1\%) } \\
& 54.9 \%(\text { CI } 50.0 \%-59.7 \%)
\end{aligned}
$$

We accept the hypothesis 8 that most German consumers have high expectations of the delivery conditions. 
There are several similarities and some differences compared to the results of other studies focused on online grocery shopping in Germany. As example, Ernst and Young (2014) states that reasons that typically draw consumers away from online markets are difficulties to assess quality and freshness of products online. This is in line with the Hypothesis 5. According the same study the final price is crucial for the consumer in Germany. The similar results were confirmed by Hypothesis 6. Fittkau and Maaß (2014) found out that a person shopping for groceries online is likely a male of 20-40 years old. Our findings do not differ but we studied the preferences of groups divided in more detail under the analysis concerning the Hypothesis 2. According to our knowledge, a number of findings presented in our study were not published in the previous studies.

\section{Graphical path model}

Based on the results from the survey data analysis a graphical path model was created. The graphical path model relies on a partial least squares structural equation model (PLS-SEM), which serves as a multivariate analysis and thus calculates all path coefficients, i.e. the relationships between the constructs in the structural model. Table 3 shows the cross-loadings of indicators and constructs of the model. Loadings above 0.70 indicate that the construct explains more than $50 \%$ of the indicators variance in case of reflective indicators.

Question QI.3: amount of money usually spent in the supermarket with ranges 10-25€, 26-45€, 46-65€, 66-85€, 86-100€ and more than $100 €$.

QII.2: the frequency of shopping online with options once a year, once a month, once a week or several times a week.

QIII.1.3: previous experience with groceries shopping, awareness of the existing possibility to shop for groceries online.

Questions QIII.2.1 to QIII.2.5: the motives for online shopping (convenience of ordering, independence from opening hours, no travel expenses/time loss, no queuing and saving time). Respondents in this question had the option to answer within a scale from $1-5$.

Questions QIII.3.3 to QIII.3.5: the reasons why not to shop groceries online by asking for control of the freshness and quality, lack of information, lack to feel, touch and smell.

Questions QIII.4.1, QIII.4.2 and QIII.4.7: sort of food which could be problematic to shop online for the consumer, such as fresh meat, fish, vegetables, fruits, milk, yogurt, butter.

The discriminant validity was confirmed by Fornell-Larcker criterion. The square root (AVE) was observed for Convenience, Lack of Trust and Problematic Food (Table 4).

The square root of the AVE of each construct is higher than the construct's highest correlation with any other construct in the model. 
Table 3. Cross-loadings of the PLS-SEM model

\begin{tabular}{|c|c|c|c|c|c|c|c|c|c|c|c|c|c|c|c|}
\hline & \multicolumn{15}{|c|}{ Constructs } \\
\hline & 总 & 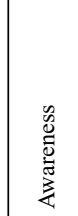 & 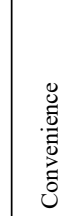 & 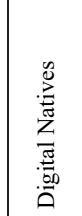 & 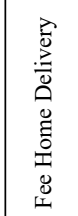 & 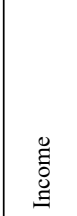 & $\stackrel{\circ}{\circ}$ & 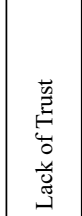 & 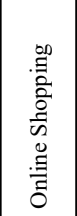 & 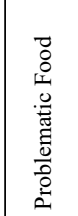 & 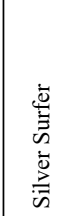 & 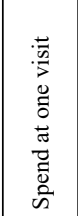 & 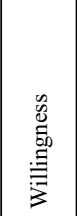 & 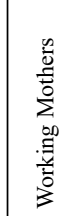 & 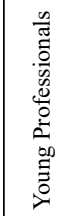 \\
\hline ge & 00 & 39 & \begin{tabular}{|l|l|}
9 & 0.003
\end{tabular} & .747 & 0.036 & 352 & -0.356 & -0.092 & -0.340 & 0.033 & 253 & .091 & .248 & 107 & 0.34 \\
\hline Incon & 2 & 3 & 95 & .350 & 322 & 000 & 091 & 0.002 & 063 & .054 & .090 & 053 & .078 & .010 & .260 \\
\hline b & 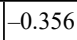 & 01 & 0.012 & 0.220 & 2 & 0.091 & 000 & 24 & 7 & 28 & 36 & 9 & 2 & 10 & 33 \\
\hline I. 3 & 91 & 021 & 129 & .138 & 0.131 & 053 & 019 & 0.025 & -0.004 & 0.106 & -0.097 & 1.000 & .052 & 0.043 & -0.19 \\
\hline \begin{tabular}{|l|} 
QII.2 \\
\end{tabular} & .340 & 0.171 & 0.137 & 0.264 & 0.083 & 0.063 & 0.307 & 0.029 & 1.000 & -0.013 & 0.010 & -0.004 & 0.533 & 0.138 & 0.310 \\
\hline QIII.1 & 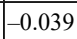 & 0 & 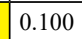 & 0 & 52 & 3 & 1 & 43 & 71 & 59 & 1 & 021 & 230 & 029 & 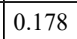 \\
\hline III & 63 & 09 & 767 & .110 & 979 & 099 & .009 & -0.089 & 008 & 144 & -0.029 & -0.027 & 49 & 074 & 0.151 \\
\hline 111. & 064 & 074 & 803 & 0.024 & 0.112 & 053 & 016 & -0.076 & 0.123 & 137 & -0.046 & 0.051 & .138 & 0.027 & 0.114 \\
\hline IIII.2 & 013 & 036 & 0.800 & -0.107 & 0.096 & .096 & -0.006 & -0.116 & 0.079 & 0.132 & -0.031 & 0.179 & 0.072 & 0.016 & -0.02 \\
\hline 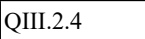 & 1 & 0.086 & 0.763 & 0.038 & 0.109 & 3 & -0.016 & -0.005 & 145 & 9 & -1 & 0 & 1 & 03 & 0008 \\
\hline | & (I) & 092 & 797 & .117 & 0 & 0.128 & 49 & -0.065 & 8 & 87 & -0.011 & ( & 17 & 33 & .020 \\
\hline III.3 & .102 & -0.047 & $7-0.138$ & 0.151 & 0.026 & 0.012 & 0.008 & 0.867 & 0.043 & -0.383 & -0.067 & -0.003 & -0.064 & 0.028 & 0.051 \\
\hline III.3.4 & .041 & -0.038 & 0.003 & 0.079 & 0.071 & -0.019 & -0.077 & 0.779 & -0.022 & -0.269 & 0.002 & 0.055 & -0.100 & -0.155 & -0.015 \\
\hline (1). & -0.068 & -0.010 & -0.042 & 121 & -0.098 & .11 & 0.000 & 0.751 & 0.046 & -0.233 & -0.001 & .017 & -0.036 & 0.012 & 0.04 \\
\hline 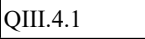 & (2) & 0.045 & 4 & 16 & 0 & 5 & -0.032 & -0.378 & -0.024 & 2 & 0 & 6 & 9 & 54 & -0.0 \\
\hline Q QIII.4.2 & 005 & 0.007 & 0.115 & -0.060 & 0.181 & 50 & -0.039 & -0.223 & 0.021 & .776 & 056 & 101 & 120 & .028 & 0.002 \\
\hline QIII.4.7 & 0.066 & 0.111 & 0.122 & -0.117 & 0.158 & 0.059 & -0.008 & -0.356 & -0.018 & 0.888 & 0.108 & 0.083 & 0.070 & 0.024 & -0.033 \\
\hline QIII.6 & 36 & .062 & 0.127 & -0.054 & 1.000 & 032 & 0.062 & 0.010 & 0.083 & 0.145 & -0.051 & 0.131 & .110 & -0.139 & 0.196 \\
\hline a dugita & -0.747 & 0.046 & -0.073 & 1.000 & -0.054 & -0.350 & 0.220 & 0.149 & 0.264 & -0.087 & -0.077 & -0.138 & 0.160 & -0.187 & 0.231 \\
\hline Interest & -0.248 & 0.230 & 0.127 & 0.160 & 0.110 & 0.078 & 0.272 & -0.084 & 0.533 & 0.084 & 0.058 & 0.052 & 1.000 & 0.083 & 0.244 \\
\hline silver su & 253 & 0.011 & -0.035 & -0.077 & -0.051 & 0.090 & -0.236 & -0.035 & 0.010 & 0.077 & 1.000 & -0.097 & 0.058 & -0.053 & -0.062 \\
\hline work.mothers & 0.107 & -0.029 & 0.035 & -0.187 & -0.139 & 0.010 & 0.010 & -0.042 & 138 & 0.042 & -0.053 & 0.043 & 33 & 1.000 & -0.16 \\
\hline oung profes. & -0.348 & 0.178 & 0.074 & 0.231 & 0.196 & 0.260 & 0.338 & 0.037 & 0.310 & -0.029 & -0.062 & -0.190 & 0.244 & -0.166 & 1.000 \\
\hline
\end{tabular}

Note: yellow indicates indicator/construct relation.

Figure 1 shows a graphical path model (PLS-SEM) that describes the willingness to shop for groceries online.

The model explains $20.1 \%$ of the variance of the willingness to shop for groceries online. Three consumer groups, working mothers, young professionals and SilverSurfers, have high willingness to shop for groceries online. SilverSurfers have the strongest willingness to shop for groceries online $(0.162$; at $\alpha=1 \%$, as $3.288>2.57)$, followed by working mothers $(0.129$; at $\alpha=1 \%$, as $2.769>2.57)$ and young professionals $(0.114$; at $\alpha=1 \%$, as $2.884>2.57$ ). The primary motive for these consumer groups to shop for groceries online is the convenience of online shopping. Working mothers and young professionals strongly benefit from timesaving, while SilverSurfers benefit from the service that reduces their heavy physical work. Another consumer group, the Digital Natives, is inherently used to shopping online, since they have grown up in the digital age. 
Table 4. Fornell-Larcker criterion-discriminant validity

\begin{tabular}{|c|c|c|c|c|c|c|c|c|c|c|c|c|c|c|}
\hline Square root (AVE) & $\stackrel{80}{<}$ & 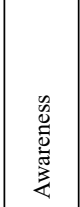 & 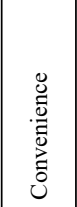 & 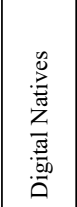 & 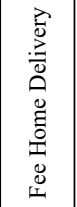 & 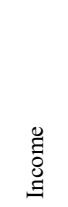 & $\stackrel{\circ}{\circ}$ & 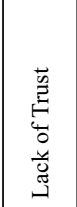 & 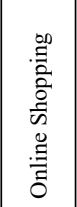 & 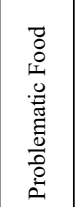 & 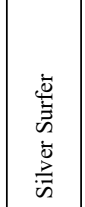 & 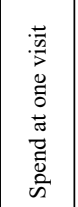 & 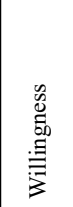 & 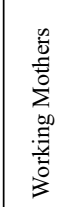 \\
\hline \multicolumn{15}{|l|}{ Age } \\
\hline Awareness & \begin{tabular}{|l|}
-0.039 \\
\end{tabular} & & & & & & & & & & & & & \\
\hline Convenience & \begin{tabular}{|l|}
0.003 \\
\end{tabular} & 0.100 & 0.786 & & & & & & & & & & & \\
\hline Dig Natives & -0.747 & 0.046 & -0.073 & & & & & & & & & & & \\
\hline Fee Home Delivery & \begin{tabular}{|l|}
0.036 \\
\end{tabular} & 0.062 & 0.127 & -0.054 & & & & & & & & & & \\
\hline Income & \begin{tabular}{|l|}
0.352 \\
\end{tabular} & 0.213 & 0.095 & -0.350 & 0.322 & & & & & & & & & \\
\hline Job & \begin{tabular}{|l|}
-0.356 \\
\end{tabular} & 0.151 & 0.012 & 0.220 & 0.062 & 0.091 & & & & & & & & \\
\hline Lack of Trust & \begin{tabular}{|l|}
-0.092 \\
\end{tabular} & -0.043 & -0.086 & 0.149 & 0.010 & 0.002 & -0.024 & 0.800 & & & & & & \\
\hline Online Shopping & \begin{tabular}{|l|}
-0.340 \\
\end{tabular} & 0.171 & 0.137 & 0.264 & 0.083 & 0.063 & 0.307 & 0.029 & & & & & & \\
\hline Problematic Food & 0.033 & 0.069 & 0.147 & -0.087 & 0.145 & 0.054 & -0.028 & -0.381 & -0.013 & 0.864 & & & & \\
\hline Silver Surfers & 0.253 & 0.011 & -0.035 & -0.077 & -0.051 & 0.090 & -0.236 & -0.035 & 0.010 & 0.077 & & & & \\
\hline Spend at one visit & 0.091 & 0.021 & 0.129 & -0.138 & 0.131 & 0.053 & 0.019 & 0.025 & -0.004 & 0.106 & -0.097 & & & \\
\hline Willingness & -0.248 & 0.230 & 0.127 & 0.160 & 0.110 & 0.078 & 0.272 & -0.084 & 0.533 & 0.084 & 0.058 & 0.052 & & \\
\hline Working Mothers & 0.107 & -0.029 & 0.035 & -0.187 & -0.139 & 0.010 & 0.010 & -0.042 & 0.138 & 0.042 & -0.053 & 0.043 & 0.083 & \\
\hline Young Professionals & -0.348 & 0.178 & 0.074 & 0.231 & 0.196 & 0.260 & 0.338 & 0.037 & 0.310 & -0.029 & -0.062 & -0.190 & 0.244 & -0.16 \\
\hline
\end{tabular}

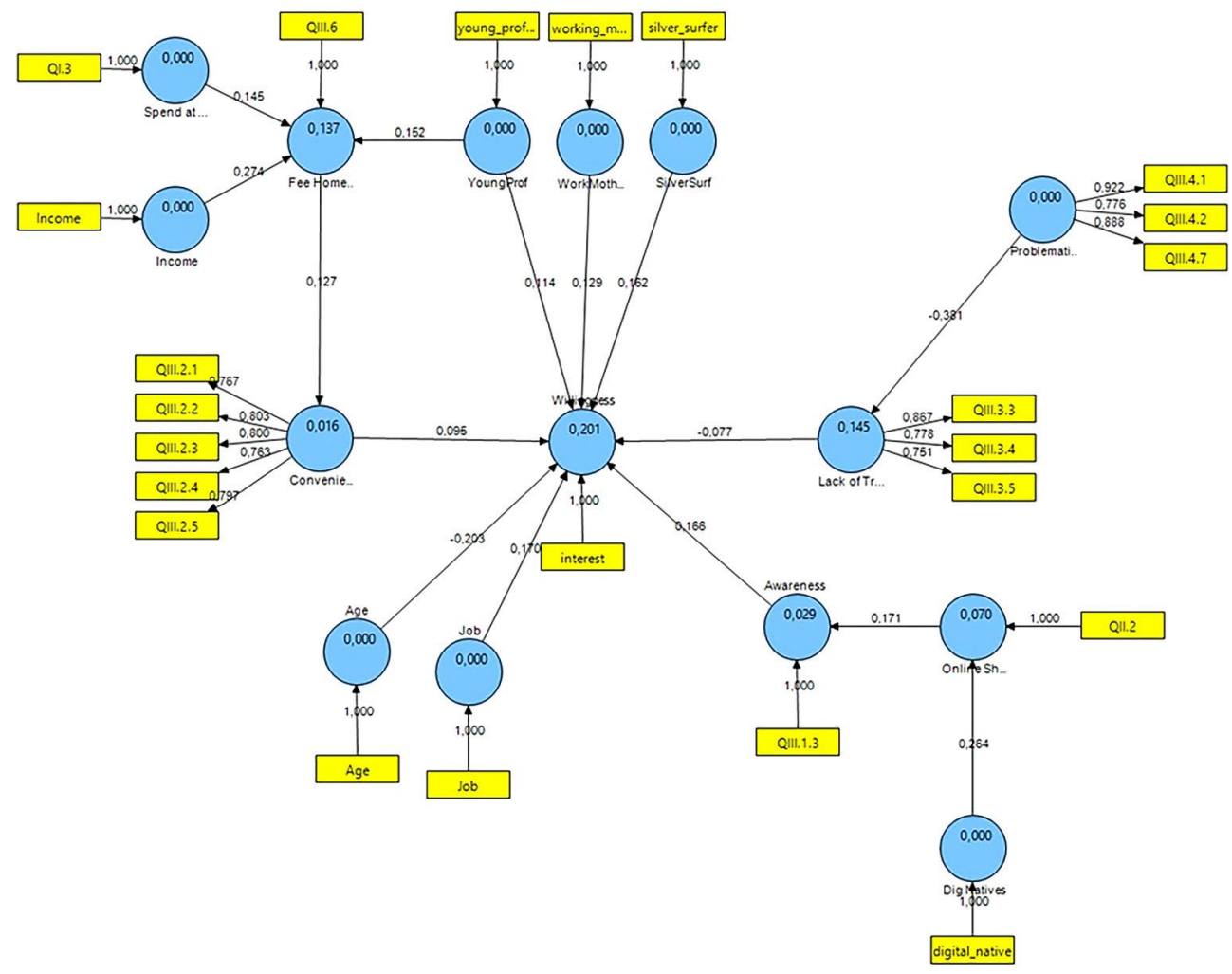

Fig. 1. Graphical path model (PLS-SEM) describing the willingness to shop for groceries online 
The awareness and knowledge of online grocery shopping is important. Being aware of the existence of online grocery shopping positively affects the willingness to shop for groceries online $(0.166$; at $\alpha=1 \%$, as $6.909>2.57)$. The majority of German consumers are not aware of the existing possibility of using online grocery shopping. German consumers are not familiar how online grocery shopping can save time and physical effort. The familiarity with online shopping has a strong influence on the awareness of online grocery shopping $(0.171$; at $\alpha=1 \%$, as $4.892>2.57)$. The strong link between the Internet familiarity, the awareness of grocery shopping and the willingness to shop online makes Digital Natives an attractive target consumer group for online shopping.

Lack of trust has a strong negative impact on the willingness to shop for groceries online, i.e. the greater the lack of trust, the lower the interest in online grocery shopping $(-0.077$; at $\alpha=10 \%$, as $1.730>1.65)$. The latent variable 'lack of trust' has a composite reliability of 0.842 , and since $0.842>0.708$, this construct is reliable. The composite reliability is the essential prerequisite for validity, and thus, the composite reliability is the most crucial criterion for the assessment of the model.

Thereby, 'lack of control' (QIII.3.3) has the highest association within this construct $(0.867$; at $\alpha=1 \%$, as $29.596>2.57)$, followed by 'insecurity about the online channel' (QIII.3.4) (0.778; at $\alpha=1 \%$, as $21.920>2.57$ ) and 'lack of feeling, touching and smelling the goods' (QIII.3.5) (0.751; at $\alpha=1 \%$, as $11.722>2.57$ ). German consumers are sceptical and worried about the Internet as a new distribution channel for groceries. This is also shown in the strong relation of the willingness to shop for "problematic foodstuff' in the online channel and the lack of trust $(-0.381$; at $\alpha=1 \%$, as $5.471>$ 2.57). The composite reliability of the latent variable 'willingness to shop for problematic foodstuff' is 0.898 , and since $0.898>0.708$, this construct is reliable. The willingness to shop for delicate foodstuff online even explains $14.5 \%$ of the variance of 'lack of trust'. Problematic foodstuffs are those kinds of food that require a special handling, e.g. cooling, and a thorough quality control before they are found to be good. The most delicate foodstuffs are fresh product $(0.922$; at $\alpha=1 \%$, as $49.242>2.57)$, followed by chilled food and dairy products $(0.888$; at $\alpha=1 \%$, as $24.106>2.57)$ and lastly fresh meat and fish $(0.776$; at $\alpha=1 \%$, as $8.791>2.57)$. Consumers are reluctant to shop for such delicate food online, since they 'do not see what they buy.

Convenience has a relation with the interest in online grocery $(0.095$; at $\alpha=10 \%$, as $1.937>1.65)$. The composite reliability of the latent variable 'convenience' is 0.890 , and since $0.890>0.708$, this construct is reliable. The need for more convenience is the prime motive for German consumers to shop for groceries online. Online grocery is considered convenient because of 'independence from opening hours' (QIII.2.2) (0.803; at $\alpha=1 \%$, as $14.146>2.57)$, followed by 'no travel expenses' (QIII.2.3) (0.800; at $\alpha=1 \%$, as $18.264>2.57$ ), 'saving time' (QIII.2.5) (0.797; at $\alpha=1 \%$, as $20.272>$ 2.57), 'convenient ordering' (QIII.2.1) (0.767; at $\alpha=1 \%$, as $11.034>2.57$ ) and 'no queuing' (QIII.2.4) (0.763; at $\alpha=1 \%$, as $13.561>2.57)$. As a result, online grocery is time-saving, e.g. the time driving from and to the supermarket or waiting at the checkout is saved, and online grocery also helps simplifying the grocery shopping trip, since consumers are independent from opening hours and from their daily schedule. The fact 
that online grocery provides relief from the physical burden, e.g. there is no need to carry heavy and bulky items or to steer the hefty shopping trolley, is not considered a convenience factor. This appreciation of the added value is also shown in the willingness to pay a fee for the online grocery service $(0.127$; at $\alpha=1 \%$, as $2.912>2.57)$. The positive relation between the willingness to pay a fee for the service and the need for convenience proves that the higher the consumer's need for convenience, the more the customer is willing to pay. Also, the willingness to pay correlates with the amount the consumer usually spends at one visit at the supermarket $(0.145$; at $\alpha=1 \%$, as $2.698>2.57$ ). The size of the shopping basket indicates how much effort the shopping trip requires. Consequently, the larger the basket and the more effort the shopping trip requires, the more is the consumer willing to pay for the more convenient online grocery service. Also, the willingness to pay has a strong relation to the consumer's income $(0.274$; at $\alpha=1 \%$, as $6.006>2.57)$. Consequently, the higher income of the consumer, the more he or she is in the position to afford the convenient service. As a result, the need for more convenience makes German consumers become potential online grocery shoppers with a high propensity to pay a fee.

\section{Conclusions}

According to the survey, $57.1 \%$ of the average consumer groups and even $85.5 \%$ of the target consumer groups can actually imagine to shop for groceries online. Due to their time constraints, online grocery appears to be especially attractive to young professionals and working mothers. The interest of SilverSurfers in online grocery in Germany is affected by two motives. First, online grocery is an effective way to overcome the physical burden of grocery shopping, which is an important benefit for the elderly suffering from reduced mobility and physical impairment. Second, elderly consumers perceive conventional grocery shopping to be a free-time activity and a welcome opportunity to be among people. Based on the results of PLS-SEM modelling we identify that the willingness to shop online for grocery is higher, when the convenience of shopping is higher too. Therefore, the business model based on delivery directly to consumer is the most preferred one. The potential e-grocery shoppers are interested in well-designed e-grocery solutions, have a clear preference for home delivery, have a strong need for convenience, which is their prime motive for shopping groceries online, and due to their appreciation of the added value of e-grocery, they are willing to pay an extra fee for the service. But they also expect the service to be highly convenient and worth its money, particularly in terms of the quality and the delivery times and conditions. The prime motive to shop for groceries online is resulting from the convenience of the online channel: online grocery shopping is time-saving and reduces physical stress.

The study also reveals that consumers are sceptical to the new distribution channel. Thus they may not forgive mistakes. Unforgivable mistakes include in particular poor product quality, unsatisfactory delivery conditions and negative user experience. German consumers do not feel the urgent need to shop for groceries online and are happy with the status quo. This may be changed by raising the awareness of consumers of the benefits of online grocery shopping. 
As a result of the analysis we conclude four recommendations for successful online grocery shopping in Germany:

1. Concentrate on the target consumer groups.

2. Raise the awareness of added value of the e-grocery service.

3. Gain the consumer's trust and confidence by making no mistakes.

4. Choose the right business model.

These four success factors enable the e-grocer to successfully meet the consumers' needs and demands towards e-grocery.

Online grocery shopping is only at a rather early development stage and thus our analysis was set out as an explorative analysis with the objective to identify German consumers' motives and demands behind the willingness to engage in online grocery shopping in order to be able to establish success factors for a prospering e-grocery business. Due to generally low experience of consumers with real online grocery shopping the limitation of the analysis is that most questions were answered in a theoretical and hypothetical way and real behaviour of consumers might differ from the answers in the questionnaire. Respondents were asked about what they thought would be their prime motives and demands towards e-grocery, if they had the possibility to do so. The study should be repeated within the next few years in order to examine how and why German consumers' interest in e-grocery changed and second in order to have a larger consumer base with actual experiences with e-grocery concerning the business model as well as motives and demands.

\section{Funding}

This work was supported by the Czech Science Foundation (GACR) under Grant No. 16-02760S.

\section{Disclosure statement}

Authors declare they have not any competing financial, professional, or personal interests from other parties.

\section{References}

Ahlert, D.; Becker, J.; Kenning, P.; Schütte, R. 2001. Internet \& Co. im handel. Strategien, Geschäftsmodelle, Erfahrungen. Berlin: Springer Verlag. https://doi.org/10.1007/978-3-642-56490-1

ATKearney. 2012. A fresh look at online grocery [online], [cited 17 November 2016]. Available from Internet: https://www.atkearney.com/consumer-products-retail/ideas-insights/featured-article/-/asset_publisher/KQNW4F0xInID/content/a-fresh-look-at-online-grocery/10192

Bakos, J. Y. 1997. Reducing buyer search costs: implications for electronic marketplaces, Management Science 43(12): 1676-1692. https://doi.org/10.1287/mnsc.43.12.1676

Bogner, T.; Brunner, N. 2007. Internationalisierung im deutschen oebensmittelhandel: möglichkeiten und grenzen der globalisierung [Internationalization in the German food trade: possibilities and limits of globalization]. Wiesbaden: Deutscher Universitätsverlag.

Boyer, K. K.; Hult, G. T. 2005. Extending the supply chain: integrating operations and marketing in the online grocery industry, Journal of Operations Management (23): 642-661.

https://doi.org/10.1016/j.jom.2005.01.003 
Bunker, D.; MacGregor, R. 2000. The marketplace as a social space: electronic grocery shopping in Australia, in V. K. Tuunainen (Ed.). Proceedings of the Second Electronic Grocery Shopping (EGS) Workshop. Helsinki School of Economics and Business Administration, Working Papers W-237. Helsinki.

Cox, R.; Brittain, P. 2004. Retailing: an introduction. Essex: Pearson Education.

Daniels, J. 2017. Online grocery sales set to surge, grabbing 20 percent of market by 2025 [online], [cited 10 July 2017]. Available from Internet: http://www.cnbc.com/2017/01/30/onlinegrocery-sales-set-surge-grabbing-20-percent-of-market-by-2025.html

Dijkstra, T. K. 2010. Latent variables and indices: Herman Wold's basic design and partial least squares, in V. Esposito Vinzi, W. W. Chin, J. Henseler, H. Wang (Eds.). Handbook of partial least squares: Concepts, methods, and applications. Berlin: Springer, 23-46.

https://doi.org/10.1007/978-3-540-32827-8_2

Dunne, P. M.; Lusch, R. F.; Carver, J. R. 2011. Retailing. $7^{\text {th }}$ ed. Mason: South-Western Cengage Learning.

Ernst \& Young. 2014. Cross channel - revolution im lebensmittelhandel [Cross channel revolution in the food trade] [online], [cited 10 July 2017]. Available from Internet: http:// www.ey.com/Publication/vwLUAssets/EY_Studie_Cross_Channel_-_Die_Revolution_im_ Lebensmittelhandel/\$FILE/EY-Cross-Channel-Die-Revolution-im-Lebensmittelhandel.pdf

Fedoseeva, S.; Hermann, R.; Nickolaus, K. 2017. Was the economics of information approach wrong all the way? Evidence from German grocery $r(\mathrm{E})$ tailing, Journal of Business Research 80: 63-72. https://doi.org/10.1016/j.jbusres.2017.07.006

Field, A. 2012. Discovering statistics using SPSS. London: SAGE Publications.

Fittkau \& Maßß. 2014. Lebensmitteleinkauf am häufigsten bei Amazon [Grocery shopping most often on Amazon] [online], [cited 10 July 2017]. Available from Internet: http://www.fittkaumaass.de/news/lebensmitteleinkauf-am-haeufigsten-bei-amazon

Goethals, F. G.; Carugati, A.; Leclercq, A. 2009. Differences in e-commerce behavior between neighboring countries, the case of France and Belgium, Database for Advances in Information Systems 40(4): 88-116. https://doi.org/10.1145/1644953.1644960

Hand, C.; Dall'Olmo Riley, F.; Harris, P.; Singh, J.; Rettie, R. 2009. Online grocery shopping: the influence of situational factors, European Journal of Marketing 43(9): 1205-1219.

https://doi.org/10.1108/03090560910976447

He, D.; Lu, Y.; Zhou, D. 2008. Empirical study of consumers' purchase intentions in C2C electronic commerce, Tsinghua Science \& Technology 13(3): 287-292.

https://doi.org/10.1016/S1007-0214(08)70046-4

Heinemann, G.; Schwarzl, C. 2010. New online retailing. Innovation and transformation. Wiesbaden: Gabler Verlag. https://doi.org/10.1007/978-3-8349-6378-9

Henry, V. 2015. The growth potential of online grocery [online], [cited 10 July 2017]. Available from Internet: https://www.igd.com/research/retail/retail-archive/articles/t/the-growth-potentialof-online-grocery/i/15874

Jayawardhena, C.; Wright, L. T. 2009. An empirical investigation into e-shopping excitement: antecedents and effects, European Journal of Marketing 43(9): 1171-1187.

https://doi.org/10.1108/03090560910976429

Kabadayi, S.; Eyuboglu, N.; Thomas, G. P. 2007. The performance implications of designing multiple channels to fit with strategy and environment, Journal of Marketing 71(4): 195-211. https://doi.org/10.1509/jmkg.71.4.195

Keh, H. T.; Shieh, E. 2001. Online grocery retailing: success factors and potential pitfalls, Business Horizons 44(4): 73-83. https://doi.org/10.1016/S0007-6813(01)80050-1 
Koch, J. V.; Cebula, R. J. 2002. Price, quality and service on the internet: sense and nonsense, Contemporary Economic Policy 20(1): 25-37. https://doi.org/10.1093/cep/20.1.25

Kotzab, H.; Teller, C. 2005. To pay or not to pay, that is the question: conceptual model and empirical results on consumers' view on home delivery, in N. Kornum, M. Bjerre (Eds.). Grocery e-commerce. Edward Elgar Publ.

Lebensmittelzeitung; Phaydon research+consulting. 2008. Lebensmittelshops im internet: das letzte große eCommerce-potenzial? [Food stores on the Internet: the last big e-commerce potential?] [online], [cited 17 November 2016]. Available from Internet: http://www.phaydon.de/ fileadmin/Bilder/Dokumente/Teaser_Studie_Lebensmittelshops_im_Internet.pdf

Levy, M.; Weitz, B. A. 2004. Retailing management. $5^{\text {th }}$ ed. Boston: McGraw-Hill Publishing. Lim, Y. J.; Osman, A.; Salahuddin, S. N.; Romle, A. R.; Abdullah, S. 2016. Factors influencing online shopping behavior: the mediating role of purchase intention, Procedia Economics and Finance (35): 401-410. https://doi.org/10.1016/S2212-5671(16)00050-2

Little, T. 2013. The Oxford handbook of quantitative methods. Oxford: Oxford University Press. https://doi.org/10.1093/oxfordhb/9780199934874.001.0001

Malone, T. W.; Yates, J.; Benjamin, R. I. 1987. Electronic market and electronic hierarchies, Communications of the ACM 30(6): 484-497. https://doi.org/10.1145/214762.214766

Neslin, S. A.; Shankar, V. 2009. Key issues in multichannel customer management: current knowledge and future directions, Journal of Interactive Marketing 23(1): 70-81.

https://doi.org/10.1016/j.intmar.2008.10.005

Passenheim, O. 2003. Multi-channel-retailing: entwicklung eines adaptiven und innovativen konzeptansatzes zur integration des internet als absatzkanal im deutschen lebensmitteleinzalhandel [Development of an adaptive and innovative concept approach for the integration of the Internet as a sales channel in the German food retail trade]. München: Rainer Hampp Verlag.

Picot-Coupey, K.; Huré, E.; Cliquet, G.; Petr, C. 2009. Grocery shopping and the internet, The International Review of Retail, Distribution and Consumer Research (4): 437-455.

https://doi.org/10.1080/09593960903331477

Plachetta, S.; Röttig, B. 2012. Ein geschäft auf allen kanälen. Lebensmittel praxis [A business on all channels. Food trade practice] [online], [cited 17 November 2016]. Available from Internet: http://lebensmittelpraxis.de/zentrale-management/5650-ein-geschaeft-auf-allen-kanaelen.html

Podaras, A.; Antlova, K.; Motejlek, J. 2016. Information management tools for implementing an effective enterprise business continuity strategy, E\&M Ekonomie a Management 19(1): 165-182. https://doi.org/10.15240/tul/001/2016-1-012

Punakivi, M.; Yrjölä, H.; Holmström, J. 2001. Solving the last mile issue: reception box or delivery box? International Journal of Physical Distribution and Logistics Management 31(6): 427439. https://doi.org/10.1108/09600030110399423

Rigdon, E. E. 1998. Structural equation modeling, in G. A. Marcoulides (Ed.). Modern methods for business research. Mahwah: Erlbaum.

Rigdon, E. E. 2012. Rethinking partial least squares path modeling: in praise of simple methods, Long Range Planning 45(5/6): 341-358. https://doi.org/10.1016/j.lrp.2012.09.010

Seitz, C. 2013. E-grocery as a new distribution channel in the German food retailing, in International Conference Management, Knowledge and Learning, 19-21 June 2013, Zadar, Croatia: ToKnowPress.

Seock, Y.; Bailey, L. R. 2008. The influence of college student's shopping orientations and gender differences on online information searches and purchase behaviours, International Journal of Consumer Studies (32): 113-121. https://doi.org/10.1111/j.1470-6431.2007.00647.x

Simová, J.; Cinkánová, L. 2016. Attributes contributing to perceived customer value in the Czech clothing on-line shopping, E\&M Ekonomie a Management 19(3): 195-206.

https://doi.org/10.15240/tul/001/2016-3-013 
Statistisches Bundesamt. 2012. Private haushalte in der informationsgesellschaft - nutzung von informations- und kommunikationstechnologien [Private households in the information society - use of information and communication technologies] [online], [cited 10 November 2015]. Available from Internet: https://www.destatis.de/DE/Publikationen/Thematisch/EinkommenKonsumLebensbedingungen/PrivateHaushalte/PrivateHaushalteIKT2150400127004.pdf? blob=publicationFile

Szász, T. 1999. Consumer direct: food-lieferdienste auf dem weg zu einem neuen handelskanal [Consumer Direct: Food delivery services on the way to a new trade channel], in T. Tomczak et al. (Eds.). Alternative Vertriebswege. Stuttgart: Schäffer-Poschel, 360-387.

Tanskanen, K.; Yrjölä, H.; Holmström, J. 2002. The way to profitable internet grocery retailing - six lessons learned, International Journal of Retail and Distribution Management 30(4): 169-178. https://doi.org/10.1108/09590550210423645

Teller, C.; Kotzab, H.; Grant, D. 2006. The consumer direct services revolution in grocery retailing: an exploratory investigation, Managing Service Quality 16(1): 78-96.

https://doi.org/10.1108/09604520610639973

Veselý, Š.; Dohnal, M. 2016. Formalized qualitative modeling of online trust: introduction of the method and a detailed example, E\&M Ekonomie a Management 19(2): 201-213.

https://doi.org/10.15240/tul/001/2016-2-014

Christian SEITZ is a PhD graduate in Economics and Management of Agriculture and Food Processing at the Faculty of Economics and Management of Slovak University of Agriculture in Nitra (Slovakia). His research is focused on economics of food retailing and e-grocery.

Ján POKRIVČÁK is an expert in the field of international economics, agricultural economics, and public economics. He was the scientific coordinator of the EU's fifth framework project Agmemod, sixth framework projects Tradeag and Agmemod 2020, and sevenths framework projects Factor Markets, Agfoodtrade, NTM Impact, Transfop and Food Secure. He was a participant to many international projects funded by World Bank, FAO, European Commission. Ján Pokrivčák graduated from Cornell University in the USA and has several publications in peer reviewed international scientific journals. He has also written several book chapters published by international publishers and participated in many international conferences. Ján Pokrivčák cooperates within his projects with leading quantitative economists, and modelers from all over the world.

Marián TÓTH is an expert in the field of agricultural economics, finance and farm performance. He graduated in Banská Bystrica (Slovakia) in Finance, Banking and Investment and did his PhD at the Faculty of Economics and Management of Slovak University of Agriculture in Nitra (Slovakia). Currently he is a postdoctoral researcher at the Department of Finance, Faculty of Economics and Management, Slovak University of Agriculture in Nitra, Slovakia. His research activities focus on finance in agriculture and risk management.

Miroslav PLEVNÝ is an expert in the field of management science, quantitative methods in economics, and logistics including the problems of supply chain management. He was the leading researcher or participating researcher in several research projects funded by the grant Agency of Czech Republic, Technological Agency of Czech Republic and others. Miroslav Plevný is the author of several articles in peer reviewed international scientific journals, and actively participated in many international conferences. He is member of Editorial boards of several peer reviewed scientific journals, member of the Expert Panel established by the R\&D Council of the Government of the Czech Republic, member of the Evaluation Panel of the Czech Science Foundation, and the vice-president of the Czech Society of Operations Research. 